\title{
The less invasive paradox, why carotid artery stenting is not suitable for the high-risk patient
}

\author{
Matthew Machin $^{1,2}$, Safa Salim ${ }^{1,2}$, Sarah Onida ${ }^{1,2}$, Alun Huw Davies ${ }^{1,2}$ \\ ${ }^{1}$ Academic Department of Vascular Surgery, Department of Surgery and Cancer, Imperial College London, London, UK; ${ }^{2}$ Imperial Vascular Unit, \\ Imperial Healthcare NHS Trust, London, UK \\ Contributions: (I) Conception and design: AH Davies, M Machin, S Onida; (II) Administrative support: AH Davies, S Onida, M Machin, S Salim; (III) \\ Provision of study materials or patients: AH Davies, S Onida; (IV) Collection and assembly of data: S Onida, M Machin, S Salim; (V) Data analysis \\ and interpretation: S Onida, M Machin, S Salim; (VI) Manuscript writing: All authors; (VII) Final approval of manuscript: All authors. \\ Correspondence to: Professor Alun Huw Davies. 4 East, Charing Cross Hospital, Fulham Palace Road, London W6 8RF, UK. \\ Email: a.h.davies@imperial.ac.uk.
}

\begin{abstract}
Carotid artery stenosis causes significant morbidity and mortality accounting for approximately $8 \%$ of all ischaemic strokes. Carotid artery stenting (CAS) offers an endovascular alternative to carotid endarterectomy (CEA), suggested as a viable option in those deemed high-risk for open CEA due to comorbidities or operative technical considerations. A number of large randomised-controlled trials (RCTs) and meta-analysis comparing CAS $v s$. CEA in unselected patient populations support the conclusion that CAS is associated with a higher risk of stroke and CEA is associated with a higher risk of myocardial infraction. Initial promise for CAS in high-risk patients was demonstrated by The Stenting and Angioplasty with Protection in Patients at High Risk for Endarterectomy (SAPPHIRE) trial that reported CAS was noninferior to CEA. However, there is evidence to suggest age-related adverse outcome in patients undergoing CAS. There is limited evidence to suggest that CEA could be suitable even in patients deemed high-risk for medical or technical reasons. Further contemporary research on the use of CAS and CEA in high-risk patients is required to re-evaluate current guidelines and high-risk criterion. It is common for a composite outcome of death, ipsilateral stroke and MI which should be questioned as subsequent quality of life is likely to differ after suffering a stroke in comparison to MI. This literature review will discuss the current evidence for CAS and CEA interventions in unselected populations and high-risk patients with carotid disease requiring intervention.
\end{abstract}

Keywords: Carotid artery stenting (CAS); carotid endarterectomy (CEA); stroke

Submitted Dec 03, 2019. Accepted for publication Apr 27, 2020.

doi: $10.21037 /$ atm-19-4085

View this article at: http://dx.doi.org/10.21037/atm-19-4085

\section{Background}

Carotid artery stenosis causes significant morbidity and mortality accounting for approximately $8 \%$ of all ischaemic strokes (1). Mortality after ischaemic stroke has been reported to be as high as $13-23 \%$ in high-income countries with an incidence of 66 per 100,000 person-years (2).

The National Institute for Health and Care Excellence (NICE) guidelines recommend that all patients suffering from transient ischaemic attacks or non-disabling strokes who have carotid stenosis of $50 \%$ to $99 \%$ undergo urgent assessment for carotid endarterectomy (CEA) (3). NICE recommend that if the carotid stenosis is $<50 \%$, despite presence of symptoms, patients should be managed with best medical therapy alone.

Carotid artery stenting (CAS) offers an endovascular alternative to CEA, suggested as a viable option in those deemed high-risk for open CEA due to comorbidities or operative technical considerations. NICE currently state 
Table 1 Randomised-controlled trial data frisk of periprocedural stroke and stroke at last follow-up after CAS vs. CEA (unclassified risk)

\begin{tabular}{|c|c|c|c|c|c|c|}
\hline Trial & $\begin{array}{l}\text { Periprocedural risk } \\
\text { of stroke after CAS }\end{array}$ & $\begin{array}{l}\text { Periprocedural risk } \\
\text { of stroke after CEA }\end{array}$ & $P$ value & $\begin{array}{l}\text { Risk of stroke at last } \\
\text { follow-up after CAS }\end{array}$ & $\begin{array}{l}\text { Risk of stroke at last } \\
\text { follow-up after CEA }\end{array}$ & $P$ value \\
\hline SPACE (8) & 42 (6.9\%) & $38(6.5 \%)$ & $\begin{array}{c}\mathrm{RR}(95 \% \mathrm{Cl}): \\
1.07(0.70-1.63)\end{array}$ & $56(9.5 \%)$ & $50(8.8 \%)$ & $\begin{array}{c}\text { RR (95\% Cl): } \\
1.10(0.75-1.61)\end{array}$ \\
\hline CREST (9) & $4.10 \%$ & $2.30 \%$ & $0.012^{*}$ & 105 (10.2\%) & 75 (7.9\%) & 0.03 \\
\hline ICSS (10) & $58(7.0 \%)$ & $27(3.3 \%)$ & $0.001^{*^{\dagger}}$ & $15.2 \%$ & $9.4 \%$ & $\begin{array}{c}\mathrm{HR}(95 \% \mathrm{Cl}): \\
5.8(2.4 \text { to } 9.3)^{\star}\end{array}$ \\
\hline EVA-3S (11) & $24(9.1 \%)$ & $9(3.4 \%)$ & Not reported & $11.10 \%$ & $6.20 \%$ & $0.03^{*}$ \\
\hline
\end{tabular}

${ }^{*}, \mathrm{P}<0.05 ;{ }^{\dagger}$, per-protocol comparison, not intention to treat comparison. CAS, carotid artery stenting; CEA, carotid endarterectomy.

CAS is a viable option after discussion at a neuroradiology multidisciplinary team meeting when CEA would not be suitable (4).

CAS was first performed using a metal stent in 1989 with subsequent introduction of neuroprotection devices in 1990 to reduce the risk of embolic events from the stent site and periprocedural stroke $(5,6)$. Medical devices have continued to improve with newer devices offering self-expanding, coated and drug-eluting stents. There is current debate over whether the less-invasive nature renders CAS a more attractive intervention in high-risk patients. Initial trials indicated that CAS was likely to be as safe as high-risk CEA based on predicted morbidity (7). However, even early small trials highlighted risk of stroke, stent deformation and restenosis (7).

This review will discuss the current evidence for CAS and CEA interventions in unselected populations and highrisk patients with carotid disease requiring intervention.

\section{Current evidence base for CAS vs. CEA in unselected populations}

A number of large randomised-controlled trials (RCTs) comparing CAS with CEA for symptomatic and asymptomatic patients exist in the literature, see Table 1.

The Stent-Protected Angioplasty versus Carotid Endarterectomy (SPACE) trial compared the use of CAS $v s$. CEA in an unselected population of symptomatic patients with high-grade carotid stenosis (8). A total of 1,214 patients with symptomatic carotid stenosis of $>70 \%$ were randomly assigned to CAS or CEA. Composite outcome included ipsilateral ischaemic stroke, any major stroke, death at 30 days and 2-year follow-up. Secondary outcome measures included carotid re-stenosis as measured on ultrasound. Composite outcome at 30 days was not significantly different for CAS vs. CEA (6.92\% vs. $6.45 \%, \mathrm{P}=0.09)$. There were no significant differences in periprocedural risk of stroke or death. In the post-procedural period up to 2 years follow-up, risk of ipsilateral ischaemic stroke was similar in the CAS arm vs. CEA (2.2\% vs. 1.9\%). Carotid re-stenosis was significantly higher in CAS vs. CEA $(10.7 \%$ vs. $4.6 \%, \mathrm{P}=0.0009)$.

Interestingly, subgroup analysis identified that there was an age-related increase in risk of composite outcome at 30 days in the CAS group $(\mathrm{P}=0.001)$, but not the CEA group. This seems counterintuitive as CAS had previously been non-inferior in higher risk (older) patients.

The Carotid Revascularization Endarterectomy versus Stenting Trial (CREST) was an RCT that randomised 2,502 patients to either CAS or CEA (9). Inclusion criteria partially mirrored those of the SPACE trial with the addition of asymptomatic patients. Included patients had symptomatic and asymptomatic carotid stenosis $>70 \%$. Primary outcome was a composite of death, stroke or MI in the perioperative period with a follow-up duration of 4 years. Primary composite outcome was similar for CAS and CEA ( $7.2 \%$ vs. $6.8 \%, \mathrm{P}=0.51)$. Stroke was significantly higher in the CAS group ( $4.1 \%$ vs. $2.3 \%, \mathrm{P}=0.012)$. Risk of biochemical myocardial infarction was significantly lower in the CAS group vs. CEA ( $1.1 \%$ vs. $2.3 \%, \mathrm{P}=0.032)$.

The risk of stroke and death was significantly higher in symptomatic patients undergoing CAS vs. CEA $(6.0 \%$ vs. $3.2 \%$, HR: $1.89 ; 95 \%$ CI: 1.11-3.21). This effect was not seen in the asymptomatic subset. At 1-year follow-up patients who developed stroke scored lower on the Medical Outcomes Study 36-Item Short-Form Health Survey but those who had an MI did not. Unexpectedly, CREST reported that outcomes were better in CEA for patients $>70$ years of age in comparison to CAS. Subsequent analysis of the CREST trial published later from Brott et al. 
Table 2 Randomised-controlled trial data for risk of periprocedural stroke and stroke at last follow-up after CAS vs. CEA in high-risk patients

\begin{tabular}{lcccccc}
\hline Trial & $\begin{array}{c}\text { Periprocedural risk } \\
\text { of stroke after CAS }\end{array}$ & $\begin{array}{c}\text { Periprocedural risk } \\
\text { of stroke after CEA }\end{array}$ & P value & $\begin{array}{c}\text { Risk of stroke at } \\
\text { last follow-up }\end{array}$ & $\begin{array}{c}\text { Risk of stroke at } \\
\text { last follow-up }\end{array}$ \\
\hline SAPPHIRE (18) & $6(3.6 \%)$ & $5(3.1 \%)$ & 0.6 & $10(6.2 \%)$ & $12(7.9 \%)$ & 0.6 \\
\hline
\end{tabular}

CAS, carotid artery stenting; CEA, carotid endarterectomy.

concluded that the 4-year rate of stroke or death was $6.4 \%$ with CAS and only 4.7\% CEA (HR =1.50, $\mathrm{P}=0.03$ ) (12).

The International Carotid Stenting Study (ICSS) also compared CAS vs. CEA as part of a National Institute for Health Research Health Technology Assessment (10). A total of 1,713 symptomatic patients with $>50 \%$ carotid stenosis were randomised. Composite outcome of stroke, death or MI within 120 days of procedure was higher in the CAS vs. CEA group ( $8.5 \%$ vs. $5.2 \%, \mathrm{P}=0.006)$. At followup, 5 -year risk of composite outcome was similar for CAS and CEA (6.4\% vs. $6.5 \%, \mathrm{P}=0.776)$. Echoing the findings of previous trials, despite the rate of composite outcome being similar, the risk of stroke was higher after CAS. The risk of any stroke at follow-up was significantly higher in CAS vs. CEA $(15.2 \%$ vs. 9.4\%, $\mathrm{P}<0.001)$. Again, increasing age was related to adverse outcome in CAS with a relative risk increase of $1.17 \%$ per 5 -year increase in age for stroke, MI or death within 30 days.

The Endarterectomy Versus Angioplasty in Patients with Symptomatic Severe Carotid Stenosis (EVA-3S) trial also concluded that the risk of periprocedural stroke or death and ipsilateral stroke after 4 years of follow-up was higher with CAS vs. CEA (11). Subsequent pooled analysis of these 4 RCTs (SPACE, CREST, ICSS and EVA-3S) again found higher risk of periprocedural stroke after CAS in comparison to CEA (13).

Importantly, studies have demonstrated this increase risk of stroke even when adjusting for age (14). Hussain et al. performed pooled analysis on 15,525 patients from an observational cohort of all individuals who underwent in CAS or CEA for asymptomatic or symptomatic carotid stenosis in Ontario, Canada (14). Composite outcome of death, stroke, or myocardial infarction at 30 days in addition to any stroke during the 13-year follow-up was higher in the CAS group vs. CEA group $(16.3 \%$ vs. $9.7 \%, \mathrm{HR}=1.57$, $\mathrm{P}<0.001)$. After adjusting for age, sex, intervention year, carotid-artery symptoms, and diabetes the increased risk of composite outcome remained.

Meta-analysis pooling data from 9 trials and 7,163 patients reflected the results of the individual trials discussed (15).
Analysis revealed a 35\% risk reduction in short-term stroke $(\mathrm{P}=0.007)$ and a $22 \%$ risk reduction in long-term stroke $(\mathrm{P}=0.006)$ for patients undergoing CEA in comparison to CAS. However, a $114 \%$ increased risk of perioperative MI for CEA vs. CAS ( $\mathrm{P}=0.003)$ was also reported. These findings have been echoed elsewhere in the literature, with repeat meta-analysis suggesting the same conclusions (16). The 2012 Cochrane systematic review and meta-analysis concluded that there was increased risk of periprocedural stroke or death with CAS compared with CEA (17).

RCTs and meta-analysis comparing CAS vs. CEA in unselected patient populations both support the conclusion that CAS is associated with a higher risk of stroke and CEA is associated with a higher risk of MI. Limited evidence suggests that patients whom developed MI had better functional outcomes in comparison to those who had a stroke.

\section{Current evidence base for CAS vs. CEA in high- risk populations}

\section{Head-to-head comparison for CAS vs. CEA in high-risk populations}

CAS showed initial promise in patients deemed to be highrisk for CEA (18). The Stenting and Angioplasty with Protection in Patients at High Risk for Endarterectomy (SAPPHIRE) trial concluded that CAS was non-inferior to CEA in patients that have at least one variable that would render CEA more challenging, see Table 2 (18). Patients are deemed to be high-risk for CEA based on medical comorbidities (e.g., heart failure, chronic obstructive pulmonary disease) and operative factors (e.g., contralateral carotid occlusion, previous neck radiotherapy). These patients are often offered CAS as an alternative procedure (6).

In this randomised-controlled trial (RCT), 334 highrisk patients were deemed medically and technically suitable to be for either CAS or CEA intervention. Composite outcome of death, stroke or myocardial infarction (MI) at 
Table 3 Observational data for risk of periprocedural stroke and stroke at last follow-up after CAS vs. CEA in high-risk patients

\begin{tabular}{|c|c|c|c|c|c|c|c|c|}
\hline Study & $\begin{array}{c}\text { Number of } \\
\text { high-risk CAS } \\
\text { procedures }\end{array}$ & $\begin{array}{c}\text { Number of } \\
\text { high-risk CEA } \\
\text { procedures }\end{array}$ & $\begin{array}{l}\text { Periprocedural } \\
\text { stroke risk in } \\
\text { high-risk group } \\
\text { after CAS }\end{array}$ & $\begin{array}{l}\text { Periprocedural } \\
\text { stroke risk in } \\
\text { high-risk group } \\
\text { after CEA }\end{array}$ & $P$ value & $\begin{array}{c}\text { Stroke risk at } \\
2 \text { years in } \\
\text { high-risk group } \\
\text { after CAS }\end{array}$ & $\begin{array}{l}\text { Stroke risk at } \\
2 \text { years in } \\
\text { high-risk group } \\
\text { after CAS }\end{array}$ & $P$ value \\
\hline Hicks (19) & 5,349 & 18,012 & $28(1.7 \%)$ & 271 (1.0\%) & $0.01^{*}$ & 32 (1.9\%) & 268 (1.0\%) & $<0.001^{*}$ \\
\hline
\end{tabular}

${ }^{*}, \mathrm{P}<0.05$. CAS, carotid artery stenting; CEA, carotid endarterectomy.

30 days was lower in the CAS compared to CEA (12.2\% vs. $20.1 \%$ ), resulting in an absolute risk reduction of $7.9 \%$ and reaching significance for non-inferiority $(\mathrm{P}=0.004)$. Importantly, the composite outcome remained lower in the CAS group at 1 year, however this did not reach significance (12.0\% vs. 20.1\%, $\mathrm{P}=0.053)$. Risk of individual components of the composite outcome were lower in the CAS vs. CEA group. The risk of major ipsilateral stroke at 1 -year was lower in the CAS vs. CEA group $(0.6 \%$ vs. $3.3 \%$, $\mathrm{P}=0.09)$.

However, little replication of this non-inferiority has been published since 2004. Retrospective analysis was performed of 51,492 patients in the Vascular Quality Initiative database who underwent CAS or CEA for symptomatic or asymptomatic carotid stenosis (19). CEA was performed in 44,912 cases and CAS was performed in the remaining 7,030 cases. Patients were classified as highrisk or normal-risk based on the Centers for Medicare and Medicaid Services policy. Overall, there was a higher risk of 30-day stroke in high-risk patients undergoing CAS in comparison to high-risk patients undergoing CEA $(2.5 \%$ vs. $1.4 \%, \mathrm{P}<0.01)$. This effect was also seen in the 2 -year risk of stroke $(2.4 \%$ vs. $1.3 \%, \mathrm{P}<0.01)$. Analysis using matched patients based on preoperative variables was also performed.

Comparing 2,920 matched pairs revealed a higher risk of 30-day and 2-year stroke in high-risk patients who underwent CAS in comparison to CEA (2-year risk: HR: 1.65, $\mathrm{P}=0.03$ ), see Table 3. From these results, Hicks et al. strongly recommended re-evaluation of national guidelines and indications for CAS.

Furthermore, Giles et al. retrospectively reviewed the Nationwide Inpatient Sample (USA) including 482,394 CEA patients and 56,564 CAS patients comparing outcomes of patients deemed to be at high-risk of undergoing CEA based on The Centers for Medicare and Medicaid Services guidelines (20). Across both normal-risk and high-risk for CEA groups, after adjustment for confounding variables, CAS was associated with double the risk of stroke or death compared with CEA (OR 2.4, 95\% CI: 2.1-2.8).
Furthermore, composite outcome of stroke and death was also higher in patients deemed high-risk for CEA in the CAS group compared to those who underwent CEA ( $3.2 \%$ vs. $1.8 \%, \mathrm{P}<0.001)$. This effect was seen across both symptomatic and asymptomatic patients. This report is unique in respect to the proportion of risk factors across both groups- $50.5 \%$ of CAS patients were deemed to be high-risk for CEA and $50.8 \%$ of CEA patients were deemed to be high-risk for CEA $(\mathrm{P}=0.58)$. This suggests that confounding by indication may not be as present as in other retrospective real-world studies.

Meta-analysis on 4,754 patients who were randomly assigned to CEA or CAS for treatment of symptomatic carotid stenosis from four RCTs in the Carotid Stenosis Trialists' Collaboration was undertaken. Patients were stratified into age groups of 5-year intervals. Periprocedural stroke (<120 days) and stroke within median follow-up time of 2.7 years was used as the primary outcome. In patients undergoing CAS, periprocedural risk of stroke and death in patients aged 65-69 years was higher vs. patients aged $<60$ years (HR 2.16; 95\% CI: 1.13-4.13). For patients aged 70-74 years undergoing CAS, this risk increased further (HR 4.01; CI 2.19-7.32). There was no relationship between age and poor outcome in patients undergoing CEA. Comparison of the two interventions in patients aged 70-74 years revealed that CAS had a higher risk of stroke and death vs. CEA (2.09, CI: 1.32-3.32).

Furthermore, evidence regarding the technical indications for CAS have also been questioned. Turley et al. retrospectively analysed data from the American College of Surgeons National Surgical Quality Initiative Project, including 12,370 patients (21). Logistic regression was performed to asses if contralateral carotid occlusion was associated with periprocedural stroke rate and if there was a higher risk in patients who underwent CAS or CEA. A total of 11,948 patients underwent CEA and 422 underwent CAS. Contralateral carotid occlusion was associated with increased risk of stroke, but the risk was the same across both CAS and CEA groups. 


\section{Non-comparative evidence for CAS in high-risk populations}

The ACCULINK for Revascularization of Carotids in High-Risk Patients trial performed CAS in 581 high-risk patients and compared it to a theoretical historical control CEA model (22). Inclusion criteria mirrored that of the insurance policy criteria for high-risk patients (NYHA class III heart failure, restenosis after previous CEA etc.). Symptomatic patients made up $24 \%$ of the trial. Composite outcome of 30-day rate of death/stroke/myocardial infarction was $8.3 \%$. Although this was deemed to be less than historical CEA control, this rate of severe adverse outcome at 30 days was high for a population with so few symptomatic patients.

The SAPHIRE registry encompasses 2,001 patients who underwent CAS for either symptomatic carotid stenosis $\geq 50 \%$ or asymptomatic carotid stenosis $\geq 80 \%$ (23). Patients had at least one physiological high-risk variable (heart failure class III/IV, MI within 4 weeks, age $>80$ years, severe pulmonary disease) or anatomical high-risk variable (contralateral carotid stenosis, previous neck radiotherapy, previous ipsilateral CEA etc.). The most common risk factors in the physiological high-risk group were age $>80$ years $(37.4 \%)$, severe pulmonary disease $(20.9 \%)$ and heart failure class III/IV or severe left ventricular dysfunction $(20.2 \%)$. In the anatomic risk population, common risk factors were previous ipsilateral CEA and restenosis $(43.3 \%)$ and contralateral carotid occlusion (23.7\%). Primary outcome was 30 -day major adverse event defined as death, myocardial infarction or stroke. Overall 30-day primary outcome was observed in $4.4 \%$ of participants. The primary outcome at 30-days was lower in the anatomic risk group $v s$. the physiological risk group ( $2.8 \%$ vs. $4.9 \%, \mathrm{P}<0.05)$. Patients who had physiological risk factors and were symptomatic at presentation had a poor outcome with 30-day stroke or death risk of $8.3 \%$, representing a high risk of periprocedural stroke.

Stanziale et al. compared outcomes for 87 patients over the age of 80 years and 295 younger patients who underwent CAS for asymptomatic and symptomatic carotid artery stenosis (24). Overall, in the age over 80 years group there was a higher risk of stroke at 30 days $(8.0 \%$ vs. $2.7 \%$, $\mathrm{P}=0.02$ ) and composite outcome of stroke, myocardial infarction, or death (9.2\% vs. 3.4\%, $\mathrm{P}=0.02)$. Comorbidities were similar across both groups.

A secondary analysis performed by Schmid et al. on 13,086 pooled patients who underwent CAS for carotid stenosis (25). As few as $36 \%$ of these patients had symptomatic carotid stenosis. Primary outcome of inhospital/periprocedural stroke or death occurred in $2.4 \%$. Regression analysis revealed that age was significantly correlated with a higher risk of in-hospital stroke or death after CAS (RR 1.54/10 year increase, 95\% CI: 1.35-1.75).

\section{Non-comparative evidence for CEA in high-risk populations}

It could be argued that the poor outcomes observed in high-risk groups undergoing CAS would be similar if those patients underwent CEA. However, recent literature suggests that CEA has better outcomes in high-risk patients.

Mozes et al. performed a retrospective analysis on patients who underwent CEA from 1998-2002 (26). The Stenting and Angioplasty with Protection in Patients at High Risk for Endarterectomy (SAPPHIRE) trial inclusion criteria was used to identify high-risk patients. From the 776 patients who underwent CEA, $42 \%(n=323)$ were deemed to be high-risk. Symptomatology and degree of stenosis were similar between the high-risk and low-risk groups. Examples of patients deemed high-risk had the following characteristics: age over 80 years $(11 \%)$, contralateral carotid occlusion (9\%), pulmonary dysfunction (7\%), high cervical lesion (5\%), and repeat carotid operation (3\%). Outcome of postoperative stroke rate was $1.4 \%$. There was no difference in postoperative in-hospital stroke rate in high-risk $v s$. low-risk patients undergoing CEA.

In a large retrospective review of the American College of Surgeons National Surgical Quality Improvement Program vascular targeted database, outcomes for patients who were high-risk of undergoing CEA for either physiological factors (e.g., recent MI or unstable angina) or anatomical factors (e.g., contralateral carotid occlusion) were compared to those with a normal operative risk (27). The analysis included 25,788 patients undergoing CEA-1,278 patients had at least one physiological risk factor, 2,823 patients had at least one anatomical risk factor, and 21,615 patients had a "normal" operative risk. Rao et al. reported a higher rate of composite 30-day stroke or death in the physiological highrisk for CEA group compared with patients with normal operative risk ( $4.6 \%$ vs. $2.3 \%, \mathrm{P}<0.001)$. This increased risk of composite 30-day stroke or death was also demonstrated in the patients at high-risk for CEA based on anatomical risk factors in comparison to patients with a normal operative risk $(3.6 \%$ vs. $2.3 \%, \mathrm{P}<0.001)$. Interestingly, 
$14,756(60 \%)$ of patients were asymptomatic, of these 621 had a physiological risk factor for CEA.

The composite 30-day stroke or death rate in this asymptomatic, physiological high-risk group, was as high as $4.7 \%$ - a rate that is well above the recommended risk profile for CEA in asymptomatic patients. Rao et al. highlighted the importance of patient selection when considering interventions for reduction in incidence of recurrent stroke. However, this data is, by definition, confounded by the physiological and anatomical criteria. There's no evidence to suggest that had these asymptomatic patients "at-risk" of CEA would have had better outcomes with CAS.

Other literature has assessed outcomes for patients who underwent CEA but also had a technical indication for CAS (28). Boitano et al. compared the outcomes after CEA from 18,551 with no history of neck radiation with 281 patients who had a known history of radiotherapy treatment to the neck. Rate of periprocedural stroke, MI, death and long-term survival was the same in both groups.

A recent retrospective analysis, pooling large numbers of patients, has indicated that CAS does not have better outcomes in higher-risk patients. It must be noted that observational studies will be subject to confounding, and indication for choosing CAS rather CEA will represent a confounding variable even in those with similar baseline characteristics. However the outcomes reported in CAS seem at odds with the less invasive nature of the procedure. It is often cited in the literature that improved CAS outcomes will arrive with evolution of stent technologies and endovascular techniques. However, Lokuge et al. performed an analysis on CAS outcomes comparing pre2005 and post 2005 data (29). It was demonstrated that CAS outcomes have not improved despite evolution in stent technologies. There is existing evidence to suggest that the higher-risk patients could be better served by CEA.

\section{Potential mechanisms for increased stroke in CAS}

There is little high-quality evidence in the literature to suggest potential mechanisms for the increased risk of stroke associated with CAS.

It has been suggested that outcomes are related to centre and operator volume with promises that as the procedure is more widely utilised outcomes may improve (30). Poorthuis et al. performed pooled analysis for operator and hospital volume for patients undergoing CAS (including 103,051 and 178,251 procedures respectively) (30). The odds of being in a high-volume centre/operator in those who suffered periprocedural stroke was significantly lower. However, these results were also replicated with CEA and unlikely to account for the entirety of the adverse periprocedural outcomes.

A known complication of CAS is hyper-perfusion syndrome which can result in intracranial haemorrhage (31). CAS has been shown to increase cerebral blood flow and alter transit time in haemodynamic studies (32). It could be argued that stenting reduces autonomic control of vessel calibre and results in less modulation of cerebral blood flow. Huibers et al. pooled 33 studies assessing 8,731 CAS procedures and estimated the risk of developing hyperperfusion syndrome to be $4.6 \%$ (33). Within this group of patients, stroke developed in $47 \%$. This is likely to be responsible for some of the periprocedural mortality and stroke risk.

Paraskevas et al. conducted a review in attempt to identify the mechanism behind the poor outcomes in symptomatic patients undergoing CAS (34). Paraskevas et al. concluded that the presence of neurological symptoms was a poor prognostic indicator for neurological outcome. They identified an increased risk of ischaemic events on magnetic resonance imaging despite the use of embolic-protection devices. The exact mechanism for this increase in cerebral ischaemic events remains unknown but Paraskevas et al. postulated the "unstable plaque theory". This theory suggests that symptomatic patients are more likely to have a plaque that is fragile to manipulation and unstable.

Hence, by manipulating a guidewire through this, one risks micro emboli showering and perioperative stroke. This theory is supported by the higher number of microembolic signals detected during CAS compared with CEA (35).

Further research into the mechanisms underpinning the increased risk around CAS is required.

\section{Conclusions}

CEA is associated with lower risk of periprocedural stroke and death in comparison to CAS in unselected patients requiring carotid intervention. Previously it was thought that CAS offered a less invasive intervention in high-risk patients with better outcomes. This is not reflected in the literature. There is evidence to suggest age-related adverse outcome in patients undergoing CAS. There is limited evidence to suggest that CEA could be suitable even in patients deemed high-risk for medical or technical reasons.

Further research into the use of CEA in high-risk 
patients is required to re-evaluate current guidelines and high-risk criterion. The use of composite outcome of death, ipsilateral stroke and MI should be questioned as subsequent quality of life is likely to differ after suffering a stroke in comparison to MI. A core outcome set for subsequent RCTs would prove useful.

\section{Acknowledgments}

Infrastructure support for this work was provided by the NIHR Imperial Biomedical Research Centre

Funding: None.

\section{Footnote}

Provenance and Peer Review: This article was commissioned by the Guest Editor (Dr. Kosmas I. Paraskevas) for the series "Carotid Artery Stenosis and Stroke: Prevention and Treatment Part I" published in Annals of Translational Medicine. The article was sent for external peer review organized by the Guest Editor and the editorial office.

Conflicts of Interest: All authors have completed the ICMJE uniform disclosure form (available at http://dx.doi. org/10.21037/atm-19-4085). The series "Carotid Artery Stenosis and Stroke: Prevention and Treatment Part I" was commissioned by the editorial office without any funding or sponsorship. The authors have no other conflicts of interest to declare.

Ethical Statement: The authors are accountable for all aspects of the work in ensuring that questions related to the accuracy or integrity of any part of the work are appropriately investigated and resolved.

Open Access Statement: This is an Open Access article distributed in accordance with the Creative Commons Attribution-NonCommercial-NoDerivs 4.0 International License (CC BY-NC-ND 4.0), which permits the noncommercial replication and distribution of the article with the strict proviso that no changes or edits are made and the original work is properly cited (including links to both the formal publication through the relevant DOI and the license). See: https://creativecommons.org/licenses/by-nc-nd/4.0/.

\section{References}

1. Flaherty ML, Kissela B, Khoury JC, et al. Carotid artery stenosis as a cause of stroke. Neuroepidemiology 2013;40:36-41.

2. Feigin VL, Lawes CM, Bennett DA, et al. Worldwide stroke incidence and early case fatality reported in 56 population-based studies: a systematic review. Lancet Neurol 2009;8:355-69.

3. Stroke N. transient ischaemic attack in over 16s: diagnosis and initial management. London: NICE 2008.

4. Carotid artery stent placement for symptomatic extracranial carotid stenosis 2011; Interventional procedures guidance [IPG389].

5. Diethrich EB, Marx P, Wrasper R, et al. Percutaneous techniques for endoluminal carotid interventions. J Endovasc Surg 1996;3:182-202.

6. Townsend RK, Fargen KM, Singh J, et al. Carotid Artery Stenting Versus Endarterectomy for Atherosclerosis: An Evidence-Based Review. Management of Cerebrovascular Disorders: Springer, 2019:399-410.

7. Roubin GS, Yadav S, Iyer SS, et al. Carotid stentsupported angioplasty: a neurovascular intervention to prevent stroke. Am J Cardiol 1996;78:8-12.

8. Eckstein HH, Ringleb P, Allenberg JR, et al. Results of the Stent-Protected Angioplasty versus Carotid Endarterectomy (SPACE) study to treat symptomatic stenoses at 2 years: a multinational, prospective, randomised trial. Lancet Neurol 2008;7:893-902.

9. Mantese VA, Timaran CH, Chiu D, et al. The carotid revascularization endarterectomy versus stenting trial (CREST) stenting versus carotid endarterectomy for carotid disease. Stroke 2010;41:S31-S34.

10. Featherstone RL, Dobson J, Ederle J, et al. Carotid artery stenting compared with endarterectomy in patients with symptomatic carotid stenosis (International Carotid Stenting Study): a randomised controlled trial with costeffectiveness analysis. Health Technol Assess 2016;20:1-94.

11. Mas JL, Trinquart L, Leys D, et al. Endarterectomy Versus Angioplasty in Patients with Symptomatic Severe Carotid Stenosis (EVA-3S) trial: results up to 4 years from a randomised, multicentre trial. Lancet Neurol 2008;7:885-92.

12. Brott TG, Hobson RW, Howard G, et al. Stenting versus endarterectomy for treatment of carotid-artery stenosis. N Engl J Med 2010;363:11-23.

13. Müller MD, von Felten S, Algra A, et al. Immediate and delayed procedural stroke or death in stenting versus endarterectomy for symptomatic carotid stenosis. Stroke 2018;49:2715-22.

14. Hussain MA, Mamdani M, Tu JV, et al. Long-term 
outcomes of carotid endarterectomy versus stenting in a multicenter population-based Canadian study. Ann Surg 2018;268:364-73.

15. Diao Z, Jia G, Wu W, et al. Carotid endarterectomy versus carotid angioplasty for stroke prevention: a systematic review and meta-analysis. J Cardiothorac Surg 2016;11:142.

16. Sardar P, Chatterjee S, Aronow HD, et al. Carotid artery stenting versus endarterectomy for stroke prevention: a meta-analysis of clinical trials. JACC 2017;69:2266-75.

17. Bonati LH, Lyrer P, Ederle J, et al. Percutaneous transluminal balloon angioplasty and stenting for carotid artery stenosis. Cochrane Database Syst Rev 2012;(9):CD000515.

18. Yadav JS, Wholey MH, Kuntz RE, et al. Protected carotidartery stenting versus endarterectomy in high-risk patients. N Engl J Med 2004;351:1493-501.

19. Hicks CW, Nejim B, Locham S, et al. Association between Medicare high-risk criteria and outcomes after carotid revascularization procedures. J Vasc Surg 2018;67:175261.e2.

20. Giles KA, Hamdan AD, Pomposelli FB, et al. Stroke and death after carotid endarterectomy and carotid artery stenting with and without high risk criteria. J Vasc Surg 2010;52:1497-504.

21. Turley RS, Freischlag K, Truong T, et al. Carotid stenting and endarterectomy and contralateral carotid occlusion. J Vasc Surg 2019;70:824-31.

22. Gray WA, Hopkins LN, Yadav S, et al. Protected carotid stenting in high-surgical-risk patients: the ARCHeR results. J Vasc Surg 2006;44:258-68.

23. Massop D, Dave R, Metzger C, et al. Stenting and angioplasty with protection in patients at high-risk for endarterectomy: SAPPHIRE Worldwide Registry first 2,001 patients. Catheter Cardiovasc Interv 2009;73:129-36.

24. Stanziale SF, Marone LK, Boules TN, et al. Carotid artery stenting in octogenarians is associated with increased adverse outcomes. J Vasc Surg 2006;43:297-304.

25. Schmid S, Tsantilas P, Knappich C, et al. Age but not sex is associated with higher risk of in-hospital stroke or death after carotid artery stenting in symptomatic

Cite this article as: Machin M, Salim S, Onida S, Davies AH. The less invasive paradox, why carotid artery stenting is not suitable for the high-risk patient. Ann Transl Med 2020;8(19):1269. doi: 10.21037/atm-19-4085 and asymptomatic carotid stenosis. J Vasc Surg 2019;69:1090-101.e3.

26. Mozes G, Sullivan TM, Torres-Russotto DR, et al. Carotid endarterectomy in SAPPHIRE-eligible high-risk patients: implications for selecting patients for carotid angioplasty and stenting. J Vasc Surg 2004;39:958-65.

27. Rao V, Liang P, Swerdlow N, et al. Contemporary outcomes after carotid endarterectomy in highrisk anatomic and physiologic patients. J Vasc Surg 2020;71:104-10.

28. Boitano LT, Ergul EA, Tanious A, et al. A Regional Experience with Carotid Endarterectomy in Patients with a History of Neck Radiation. Ann Vasc Surg 2019;54:12-21.

29. Lokuge K, de Waard D, Halliday A, et al. Meta-analysis of the procedural risks of carotid endarterectomy and carotid artery stenting over time. Br J Surg 2018;105:26-36.

30. Poorthuis MHF, Brand EC, Halliday A, et al. High operator and hospital volume are associated with a decreased risk of death and stroke after carotid revascularization: a systematic review and meta-analysis. Ann Surg 2019;269:631-41.

31. Abou-Chebl A, Yadav JS, Reginelli JP, et al. Intracranial hemorrhage and hyperperfusion syndrome following carotid artery stenting: risk factors, prevention, and treatment. JACC 2004;43:1596-601.

32. Duan Y, Li G, Yang Y, et al. Changes in cerebral hemodynamics after carotid stenting of symptomatic carotid artery. Eur J Radiol 2012;81:744-8.

33. Huibers AE, Westerink J, de Vries EE, et al. Editor's choice-cerebral hyperperfusion syndrome after carotid artery stenting: a systematic review and meta-analysis. Eur J Vasc Endovasc Surg 2018;56:322-33.

34. Paraskevas KI, Mikhailidis DP, Veith FJ. Mechanisms to explain the poor results of carotid artery stenting (CAS) in symptomatic patients to date and options to improve CAS outcomes. J Vasc Surg 2010;52:1367-75.

35. Crawley F, Clifton A, Buckenham T, et al. Comparison of hemodynamic cerebral ischemia and microembolic signals detected during carotid endarterectomy and carotid angioplasty. Stroke 1997;28:2460-4. 